\title{
PENGEMBANGAN JARINGAN PRASARANA JALAN KAWASAN JABODETABEK SEBAGAI PENUNJANG KEGIATAN DRY PORT
}

\author{
Sahar Andhika Putra, SH, MH \\ Dosen STTD \\ Jl. Raya Setu No. 89, Cibuntu, \\ Cibitung, Bekasi 17520 \\ Telp./Fax : (021) 8254640
}

\author{
Dr. Effendi Prih Raharjo, MT \\ Dosen STTD \\ Jl. Raya Setu No. 89, Cibuntu, \\ Cibitung, Bekasi 17520 \\ Telp./Fax : (021) 8254640
}

\author{
Dessy Angga A. MT \\ Dosen STTD \\ Jl. Raya Setu No. 89, Cibuntu, \\ Cibitung, Bekasi 17520 \\ Telp./Fax : (021) 8254640
}

\author{
Novitasari, M.Eng \\ Dosen STTD \\ Jl. Raya Setu No. 89, Cibuntu, \\ Cibitung, Bekasi 17520 \\ Telp./Fax : (021) 8254640
}

\author{
Anasta Wirawan, MM \\ Dosen STTD \\ Jl. Raya Setu No. 89, Cibuntu, \\ Cibitung, Bekasi 17520 \\ Telp./Fax : (021) 8254640
}

\begin{abstract}
ABSTRAKSI
Cikarang Dry Port terletak secara strategis di Kawasan Industri Jababeka pada jantung kawasan manufaktur terbesar di Jawa Barat dan di Indonesia, rumah bagi lusinan Kawasan Industri dengan lebih dari 2.500 perusahaan, baik perusahaan multinasional maupun usaha kecil dan menengah

(UKM).

Antisipasi dampak perlu dilakukan untuk menjamin keselamatan pada akses keluar-masuk Kawasan Industri Jababeka, kemudahan manuver pada akses keluar-masuk, serta pemisahan sirkulasi pejalan kaki dengan sirkulasi kendaraan.

Potensi tarikan perjalanan yang menuju Kawasan Jababeka pada tahun mendatang perlu dilakukan antara lain, Waktu Operasional Karyawan, Penggunaan Bus Angkutan Jemputan Karyawan, Penyediaan Mess karyawan/Condominium khusus untuk karyawan Kawasan Jababeka, Penyediaan angkutan internal kawasan Jababeka dan fasilitas pejalan kaki,Pengaturan sirkulasi kendaraan internal didalam masing-masing kawasan dan juga antar kawasan Jababeka secara umum, Adanya Manajemen Operasional Pengangkutan Barang.

Usulan dengan perubahan desain dan dilakukannya rekasaya pada skenario 1, 2 dan 3 perlu adanya koordinasi dengan instansi terkait dengan upaya menghindari potensi kemacetan di beberapa ruas jalan dan persimpangan kawasan cikarang dry port.
\end{abstract}

\begin{abstract}
Cikarang Dry Port is strategically located in Jababeka Industrial Estate in the heart of the largest manufacturing district in West Java and in Indonesia, as home to dozens of Industrial Zone with more than 2,500 companies, both multinationals and small and medium enterprises (SMEs).

Anticipate the impact needs to be done to ensure the safety of the in and out access of the Jababeka Industrial Estate, ease of maneuverability on in and out access, as well as the separation of pedestrian circulation with the circulation of vehicles.

Potential traction trip to the Jababeka Region in the coming year needs to be done, among others, Employees Operational Time, The use of Employess Pickup Bus Transportastion, Mess Supply for employee / Condominium for employees in Jababeka
\end{abstract}


Region, provision of internal transport in Jababeka area and pedestrian facilities, vehicle circulation internal settings in each of the regions and also between Jababeka in general, the existence of Transport Cargo Operations Management.

Proposed by design changes and does engineering in scenario 1, 2 and 3 need to coordinate with relevant agencies to attempt to avoid potential congestion on several roads and intersections cikarang dry port area.

\section{PENDAHULUAN}

\section{A. Latar Belakang}

Cikarang Dry Port terletak secara strategis di Kawasan Industri Jababeka pada jantung kawasan manufaktur terbesar di Jawa Barat dan di Indonesia, rumah bagi lusinan Kawasan Industri dengan lebih dari 2.500 perusahaan, baik perusahaan multinasional maupun usaha kecil dan menengah (UKM). Sebagai perpanjangan pintu gerbang Pelabuhan Internasional Tanjung Priok, segala macam dokumen serta perizinan dapat diselesaikan di dalam Cikarang Dry Port. Cikarang Dry Port mulai dioperasikan pada tahun 2010 dan terletak di jantung kawasan manufaktur terbesar di Indonesia di sepanjang kawasan Bekasi-Cikampek, Jakarta Timur. Sekitar 200 hektar dialokasikan untuk dry port yang mudah diakses menggunakan jalan raya dan kereta api. Cikarang Dry Port (CDP) menawarkan layanan satu atap untuk penanganan kargo serta solusi logistik untuk ekspor dan impor internasional, demikian pula untuk distribusi domestik.

Cikarang Dry Port menerapkan The SAFE Framework of the World Customs Organisation dan standar Internasional untuk meningkatkan perdagangan internasional dan return value untuk memasok pengusaha supply chain baik di Indonesia maupun di luar negeri.

Cikarang Dry Port didesain sebagai Kawasan Pelabuhan Pelayanan Terpadu (KPPT) atau istilah yang lebih populer layanan satu atap kepelabuhanan untuk penanganan kargo. Dengan layanan satu atap itu maka proses dokumentasi dan pemeriksaan terkait Bea Cukai, Karantina Hewan dan Karantina Tumbuhan diselesaikan di sini. Didukung dengan INSW, layanan dan fasilitas yang terpadu ini akan memberi kemudahan, kepastian pelayanan, dan meningkatkan produktivitas. Selain menggunakan fasilitas terminal untuk dry cargo, fasilitas reefer container (peti kemas berpendingin), dan pemeriksaan jalur merah sudah dapat dilayani di dalam terminal Cikarang Dry Port dengan tarif yang transparan.

Berdasarkan uraian tersebut diatas, maka penyususn tertarik untuk mengkaji lebih dalam dan mengemukakan dalam bentuk sebuah penelitian dengan judul "PENGEMBANGAN 


\section{JARINGAN PRASARANA JALAN SEBAGAI PENUNJANG CIKARANG DRY PORT (CDP)"}

\section{B. Perumusan Masalah}

Berdasarkan latar belakang masalah diatas, maka penulis mengidentifikasikan masalahmasalah yang ada sebagai berikut :

a. Karena akan tersambungnya jalur lintas angkutan barang dari pasoso ke Tanjung Priok maka demand yang ada di Cikarang Dry Port (CDP) akan meningkat;

b. Belum diaturnya jaringan jalan di sekitar Cikarang Dry Port (CDP);

c. Belum adanya desain simpul yang baik untuk dapat memfasilitasi deman di Cikarang Dry Port.

\section{Tujuan Penilitian}

Tujuan dari adanya penelitian Pengembangan Jaringan Prasarana Jalan Sebagai Penunjang Cikarang Dry Port (CDP) adalah sebagai berikut :

a. Mengidentifikasi unjuk kerja jaringan eksisting di sekitar Cikarang Dry Port (CDP).

b. Mengetahui demand setelah terkoneksi jaringan kereta api Cikarang sampai dengan Tanjung Priuk.

c. Menghitung unjuk kerja jaringan jalan di sekitar Cikarang Dry port (CDP) setelah terkoneksi dengan jaringan kereta api.

d. Membandingkan kinerja jaringan jalan eksisting sebelun dan setelah terkoneksi dengan jaringan kereta api.

e. Menguslkan rekayasa ruas dan simpang guna meningkatkan kinerja dan aksesibilitas pada jaringan.

\section{Ruang Lingkup Penelitian}

Ruang Lingkup dalam penulisan penelitian ini hanya akan membahas pada pengaturan jaringan jalan di sekitar Cikarang Dry Port saja tidak sampai dengan mendisain simpulsimpul yang ada di sekitar Cikarang Dry Port (CDP), selain itu penyusun juga membatasi untuk melakukan analisa data demand pada jaringan menggunakan alat bantu (software) Vissum. 


\section{METODOLOGI PENELITIAN}

\section{A. Bagan Penelitian.}

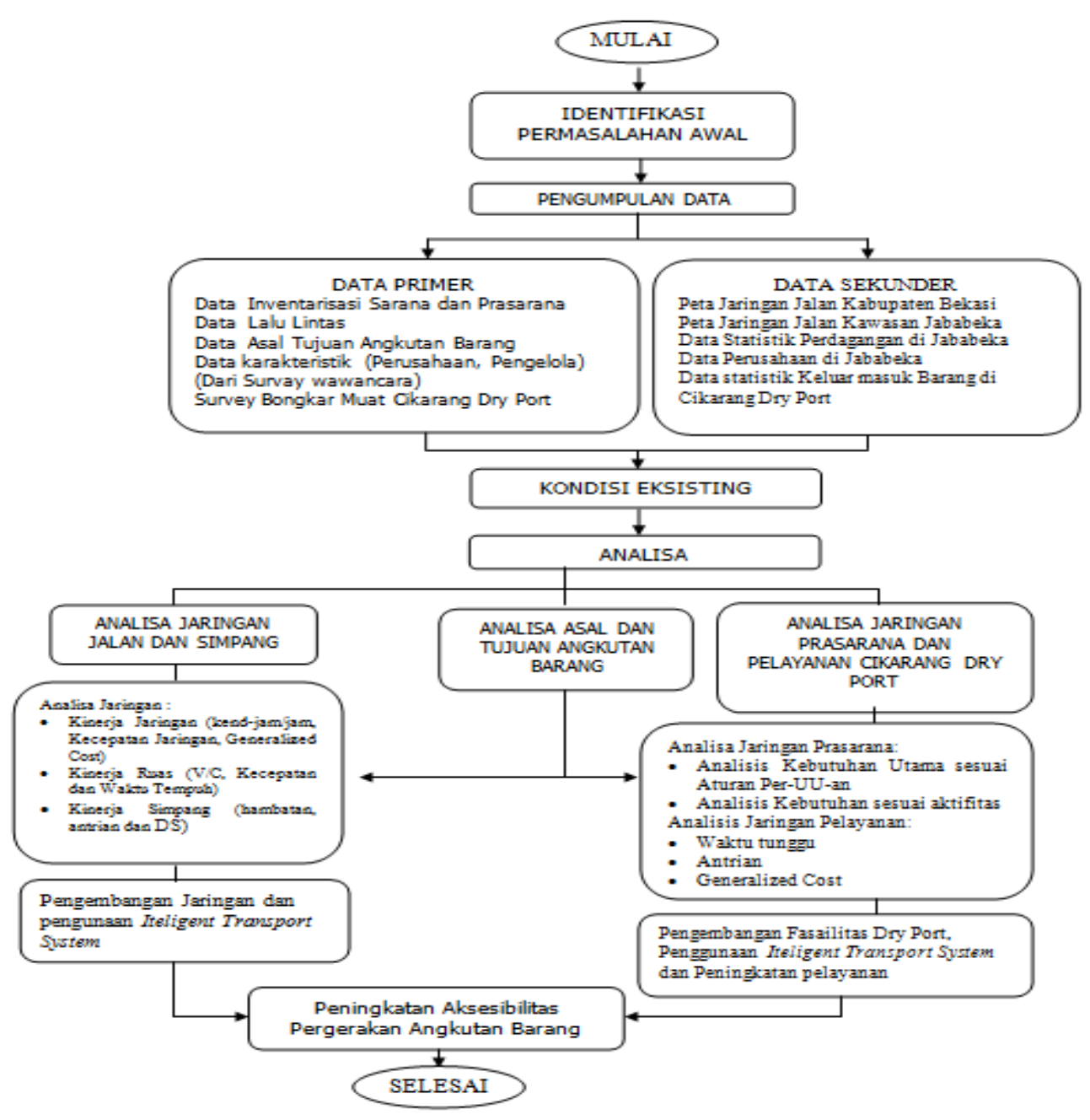

Tabel Tingkat Bangkitan Perjalanan Untuk Kondisi Eksisting

Kawasan Jababeka 2016

\begin{tabular}{|c|c|c|c|c|c|c|c|c|c|}
\hline \multicolumn{2}{|c|}{ Uraian } & \multirow{2}{*}{\multicolumn{2}{|c|}{ Luasan }} & \multicolumn{2}{|c|}{ Pagi } & \multicolumn{2}{|c|}{ Siang } & \multicolumn{2}{|c|}{ Sore } \\
\hline \multirow[b]{2}{*}{ TIAP KAWASAN } & \multirow{2}{*}{\begin{tabular}{|c|} 
Peruntukan \\
Lalu Lintas Ekternal/ \\
$100 \mathrm{~m} 2$ GFA \\
\end{tabular}} & & & \multirow{2}{*}{$\begin{array}{c}\text { Masuk } \\
0,21\end{array}$} & \multirow{2}{*}{\begin{tabular}{|c|} 
Keluar \\
0,15
\end{tabular}} & \multirow{2}{*}{\begin{tabular}{|c|} 
Masuk \\
0,16
\end{tabular}} & \multirow{2}{*}{\begin{tabular}{|c|} 
Keluar \\
0,12
\end{tabular}} & \multirow{2}{*}{\begin{tabular}{|c|} 
Masuk \\
0,24
\end{tabular}} & \multirow{2}{*}{\begin{tabular}{|c|} 
Keluar \\
0,18
\end{tabular}} \\
\hline & & $(\mathrm{m} 2)$ & $(/ 100 \mathrm{~m} 2)$ & & & & & & \\
\hline \multirow{2}{*}{$\begin{array}{c}\text { Kawasan Jababeka } \\
1\end{array}$} & $\begin{array}{c}\text { COMERCIAL MIX } \\
\text { USE } \\
\end{array}$ & 1900000 & 19000 & 3990 & 2850 & 3040 & 2280 & 4560 & 3420 \\
\hline & $\begin{array}{l}\text { INDUSTRIAL } \\
\text { ESTATE }\end{array}$ & 6000000 & 60000 & 12600 & 9000 & 9600 & 7200 & 14400 & 10800 \\
\hline \multirow{3}{*}{$\begin{array}{c}\text { Kawasan Jababeka } \\
2\end{array}$} & $\begin{array}{c}\text { COMERCIAL MIX } \\
\text { USE }\end{array}$ & 600000 & 6000 & 1260 & 900 & 960 & 720 & 1440 & 1080 \\
\hline & \begin{tabular}{|c|} 
INDUSTRIAL \\
ESTATE
\end{tabular} & 1200000 & 12000 & 2520 & 1800 & 1920 & 1440 & 2880 & 2160 \\
\hline & RESIDENTIAL & 500000 & 5000 & 1050 & 750 & 800 & 600 & 1200 & 900 \\
\hline
\end{tabular}




\begin{tabular}{|c|c|c|c|c|c|c|c|c|c|}
\hline & ESTATE & & & & & & & & \\
\hline \multirow{2}{*}{$\begin{array}{c}\text { Kawasan Jababeka } \\
3 \& \text { CDP }\end{array}$} & $\begin{array}{c}\text { COMERCIAL MIX } \\
\text { USE }\end{array}$ & 1700000 & 17000 & 3570 & 2550 & 2720 & 2040 & 4080 & 3060 \\
\hline & $\begin{array}{l}\text { INDUSTRIAL } \\
\text { ESTATE }\end{array}$ & 2000000 & 20000 & 4200 & 3000 & 3200 & 2400 & 4800 & 3600 \\
\hline \multirow{2}{*}{ PERUMAHAN } & $\begin{array}{c}\text { COMERCIAL MIX } \\
\text { USE }\end{array}$ & 500000 & 5000 & 1050 & 750 & 800 & 600 & 1200 & 900 \\
\hline & \begin{tabular}{|c|}
$\begin{array}{c}\text { RESIDENTIAL } \\
\text { ESTATE }\end{array}$ \\
\end{tabular} & 2000000 & 20000 & 4200 & 3000 & 3200 & 2400 & 4800 & 3600 \\
\hline \multicolumn{2}{|c|}{ Total } & 13900000 & 139000 & 29190 & 20850 & 22240 & 16680 & 33360 & 25020 \\
\hline \multicolumn{4}{|c|}{ Jumlah Bangkitan/Tarikan Area } & 29190 & 20850 & 22240 & 16680 & 33360 & 25020 \\
\hline
\end{tabular}

Sumber: Hasil Analisa, 2016

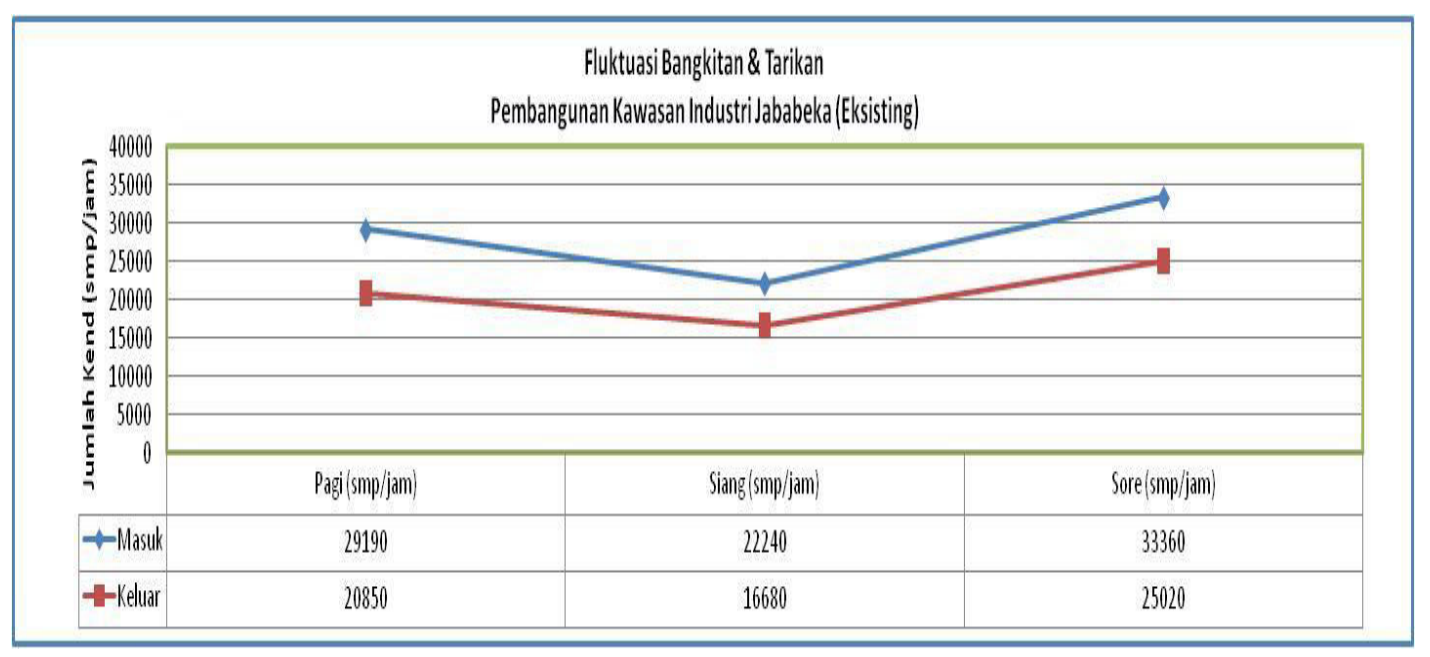

Dari hasil tabel diatas dan gambar diatas dapat dilihat potensi tarikan dan bangkitan pembangunan Kawasan Industri Jababeka Tahun 2016yaitu pada jam sibuk sore hari. Selanjutnya unutk analisis lebih lanjut besaran tarikan dan bangkitan perjalanan menjadi dasar acuan dalam jam perencanaan dan besaran potensi tarikan dan bangkitan yang mewakili dalam perjalanan 1 (satu) hari. Hal ini dikarenakan nilai tertinggi volume lalu lintas pada ruas jalan Industrial Lots dan Pergudangan terjadi pada sore hari. Dan berdasarkan tabel diatas dapat diketahui bahwa jumlah bangkitan perjalanan untuk kondisi terbangunnya Kawasan Industri Jababeka Tahun 2016 adalah sebesar 33360 smp/jam dan jumlah tarikan perjalanan kondisi terbangunnya Kawasan Jababeka I, II, dan III Tahun 2016 adalah sebesar 25050 smp/jam. 
Tabel Perbandingan Unjuk Kerja Jaringan Jalan

\begin{tabular}{|c|c|c|c|c|c|c|}
\hline \multirow{2}{*}{ No } & Parameter & \multicolumn{2}{|c|}{ Tahun 2016} & \multicolumn{2}{|c|}{ Tahun 2021 } \\
\cline { 3 - 6 } & & $\begin{array}{c}\text { Tanpa } \\
\text { Pembangunan }\end{array}$ & $\begin{array}{c}\text { Do- } \\
\text { Nothing }\end{array}$ & $\begin{array}{c}\text { Tanpa } \\
\text { Pembangunan }\end{array}$ & Do-Nothing & $\begin{array}{c}\text { Do- } \\
\text { Something }\end{array}$ \\
\hline 1 & Total Waktu Perjalanan (kend-jam) & 2862,1 & 3496,1 & 4019,1 & 4401,1 & 4367,1 \\
\hline 2 & $\begin{array}{c}\text { Total Panjang Perjalanan (Kend- } \\
\text { Km) }\end{array}$ & 67102,9 & 70346,9 & 71578,9 & 72099,9 & 72620,9 \\
\hline 3 & Kecepatan Jaringan (Km/Jam) & 32,75 & 29,38 & 27,34 & 23,85 & 24,80 \\
\hline 4 & Panjang Antrian (Kend) & 185,2 & 289,2 & 313,2 & 387,2 & 376,2 \\
\hline 5 & Konsumsi Bahan Bakar (Liter) & 8591,2 & 8733,2 & 9168,2 & 10064,2 & 9297,2 \\
\hline
\end{tabular}

Sumber : Hasil AnalisisDari Tabel diatas dapat dilihat bahwa pada tahun 2016 total waktu perjalanan sebelum dibangunnya Kawasan Industri Jababeka sebesar 2862,1 kend/jam, dan dengan kecepatan jaringan sebesar 34,75 km/jam. Pada kondisi Do-Nothing total waktu perjalanan menjadi sebesar 3496,1 kend-jam, dengan kecepatan jaringan sebesar 29,38 km/jam.

Sedangkan kondisi tanpa pembangunan kawasan industri Jababeka di tahun 2021, total waktu perjalanan sebesar 4019,1 kend-jam dengan kecepatan jaringan sebesar 27,34 $\mathrm{km} / \mathrm{jam}$. Sedangkan pada saat Kawasan Industri Jababeka dioperasikan secara maksimal tanpa pengaturan pada tahun 2021 kondisi Do-Nothing total waktu perjalanan disekitar lokasi di bangunnya Kawasan Industri Jababeka sebesar 4401,1 kend-jam, dengan kecepatan jaringan sebesar 23,85 km/jam. Dan pada saat seluruh Kawasan Industri Jababeka terbangun pada tahun 2023 kondisi Do-Nothing total waktu perjalanan disekitar lokasi di bangunnya Kawasan Industri Jababeka sebesar 5262,1 kend-jam, dengan kecepatan jaringan sebesar 14,87 km/jam. Untuk kondisi Do- Something pada tahun 2021 (Skenario 1) total waktu perjalanan 4367,1 kend-jam, dengan kecepatan jaringan naik menjadi $24,8 \mathrm{~km} / \mathrm{jam}$.

\section{Manajemen Lalu Lintas Cikarang Dry Port (CDP)}

Pada tahap konstruksi pembangunan kawasan industri Jababeka V, VI, dan VII dilakukan tentu terdapat pergerakan kendaraan berat dalam distribusi barang yang dibutuhkan dalam masa pembangunan. Oleh karena itu, untuk menjamin kelancaran dan keselamatan lalu lintas disekitarnya maka perlu adanya manajemen lalu lintas. Adapun manajemen lalu lintas yang dilakukan pada lokasi pembangunan kawasan antara lain sebagai berikut:

\section{1) Sirkulasi Angkutan Barang}


Pada pengaturan sirkulasi internal angkutan barang pada pembangunan kawasan Jababeka V, VI, dan VII ini berkaitan dengan sirkulasi pada masing-masing kawasan.Terkait dengan informasi kondisi lapangan untuk proses pembangunan tidak diperoleh maka perlu dilakukan pengaturan terkait dengan sebagai berikut:

a. Pengaturan terikait dengan akses keluar masuk kendaraan barang;

b. Pengaturan lokasi bongkar muat barang guna melakukan pengintegrasian kendaraan barang;

c. Pengaturan lokasi parkir kendaraan barang; dan

d. Pengaturan lokasi antrian kendaraan barang.

\section{2) Manajamen dan Rekayasa Simpang Pintu Tol Cikarang Barat I}

Dari berbagai potensi masalah yang ada menyebabkan simpang tidak dapat bekerja secara maksimal sehingga perlu adanyaredesain simpang tol Cikarang Barat I antara lain sebagai berikut:

a. Redesain radius simpang belok kiri arah KJI sesuai dengan jenis kendaraan rencana;

b. Terkait dengan adanya persilangan kendaraan antara kendaraan belok kanan arah Lippo Cikarang dengan kendaraan menerus, maka terkait dengan itu perlu dilakukan aturan khusus yaitu untuk semua arus lalu lintas menerus menuju KIJ diharuskan melewati fly over, terkait dengan tata guna lahan disekitar simpang perlu dilakukan perubahan pintu keluar;

c. Diberlakukan larangan U-Turn agar tidak mengganggu kelancaran lalu lintas di simpang Tol CIkarang Barat I;

d. Pemasangan rambu larangan berhenti di sekitar simpang tol Cikarang Barat I, sehingga arus kendaraan dapat berjalan lancar;

e. Melakukan pemisahan secara langsung dari gerbang tol Cikarang Barat I, sehingga kendaraan baik dari KIJ maupun Lippo Cikarang tidak saling menutup.

Adapun gambaran manajemen dan rekayasa lalu lintas pada simpang tol Cikarang Barat I dapat dilihat pada gambar sebagai berikut.

\section{3) Manajamen dan Rekayasa Simpang Jl. Industri Jababeka-Jl.Kalimalang}

Dari berbagai potensi masalah yang ada menyebabkan simpang tidak dapat bekerja secara maksimal sehingga perlu adanya redesain simpang ruas jalan industri Jababeka-ruas jalan Kalimalang antara lain sebagai berikut:

a. Meredesain radius simpang belok kiri arah menuju tol sesuai dengan jenis kendaraan rencana; 
b. Meminimalkan adanya jalinan pada simpang atau dengan memperpanjang jarak jalinan karena pada kondisi eksisting jarak jalinan pendek;

c. Memfungsikan ruas jalan yang tidak dipergunakan pada ruas jalan kalimalang arah deltamas;

d. Merubah ruas jalan arah Deltamas dari dua arah menjadi satu arah untuk meningkatkan keselamatan dan juga kelancaran lalu lintas.

Adapun gambaran manajemen dan rekayasa lalu lintas pada simpang ruas jalan industri Jababeka-ruas jalan Kalimalang dapat dilihat pada gambar sebagai berikut.

\section{1) Manajamen dan Rekayasa Simpang Jababeka Pintu I dan II}

Dari gambar diatas dapat diketahui bahwa terdapat beberapa permasalahan yang ada pada simpang pintu Jababeka I dan II yang berkontribusi terhadap kemacetan antara lain sebagai berikut :

a. Kondisi radius simpang yang tidak mencukupi terkait dengan kendaraan rencana;

b. Adanya arus persilangan antara kendaraan keluar masuk kawasan dengan kendaraan menerus;

Adapun gambaran manajemen dan rekayasa lalu lintas pada simpang Jababeka I dan II dapat dilihat pada gambar sebagai berikut.

\section{2) Manajamen dan Rekayasa Simpang Stasiun Lemah Abang}

Simpang Stasiun Lemah Abang merupakan simpang yang terbentuk dari pertemuan ruas jalan Cibarusah dengan ruas jalan Urip Sumoharjo, dimana ruas jalan Cibarusah merupakan ruas jalan penghubung menuju Kawasan Industri Jababeka/kawasan Lippo Cikarang/tol Jakarta-Cikampek. Sedangkan ruas jalan Urip Sumoharjo merupakan ruas jalan yang menghubungkan antara Kota Bekasi dengan Karawang.Sehingga pada ruas jalan Cibarusah ini merupakan akses terdekat menuju kawasan Jababeka, kawasan Lippo CIkarang dan juga akses tol dari arah Karawang.Adapun visualisasi kondisi simpang Stasiun Lemah Abang dapat dilihat pada gambar sebagai berikut.

Dari berbagai potensi masalah yang ada menyebabkan simpang tidak dapat bekerja secara maksimal sehingga perlu adanya redesain simpang Stasiun Lemah Abang antara lain sebagai berikut:

a. Memperbaiki ruas jalan masuk perlintasan pada ruas jalan Cibarusah;

b. Memperbaiki ruas jalan pada perlintasan dengan membuat desain tinggi jalan perlintasan sama dengan tinggi rel; 


\title{
Manajemen Operasional Angkutan Barang \\ Perencanaan Spesifikasi Kendaraan Pengangkut
}

\begin{abstract}
A. Muatan Sumbu Terberat (MST)
Muatan Sumbu Terberat (MST) kendaraan barang yang direncanakan harus sesuai dengan kelas jalan yang disediakan. Apabila kelas jalan tidak sesuai dan tidak dapat memikul beban kendaraandiatasnya dalam jangka panjang akan mengakibatkankerusakan permukaan jalan dan berimplikasi pada penurunan kecepatan dan potensi terjadinya kecelakaan bagi lalu lintas yang lain.
\end{abstract}

\section{B. Standarisasi Desain Kendaraan}

Kendaraan barang dengan standard desain akan mengurangi kelebihan muatan (overload), kelebihan muatan akan berakibat pada kinerja atau performa kendaraan saat mendistribusikan barang, selain itu dengan muatan berlebih akan mengakibatkan kondisi jalan yang dilewati kendaraan mengalami kerusakan-kerusakan secara terus menerus.

\section{Penjadwalan Kendaraan Angkutan Barang}

Penjadwalan adalah Pengaturan pemberangkatan suatu kendaraan barang pada rute yang telah ditetapkan dengan tujuan agar operator dapat menyesuaikan kebutuhan armada untuk mengangkut hasil produksi.

Dalam usaha membentuk suatu penjadwalan yang baik maka perlu perencanaan yang baik sehingga penjadwalan yang dilakukan bisa lebih efisien dan efektif. Adapun tahapan - tahapan yang perlu diperhatikan adalah sebagai berikut :

1. Penyusunan jadwal pemberangkatan dan kedatangan armada

2. Penyusunan awak dari armada

3. Headway antar kendaraan

4. Frekuensi dari pada pelayanan

5. Perubahan dari pada frekuensi (pengaruh dari peak dan off peak)

Dalam penyusunan penjadwalan keberangkatan dan kedatangan kendaraan ditujukan untuk dapat memberikan kebutuhan akan armada yang nantinya digunakan sebagai alat angkut hasil produksi. 
Frekuensi kendaraan berat dapat diatur berubah ubah sesuai dengan kebutuhan ketika pada peak hour maka frekuensi dapat dikurangi sedangkan pada off peak frekuensi ditambahhal tersebut dilakukan untuk mengoptimalkan waktu perjalanan dan biaya operasi.

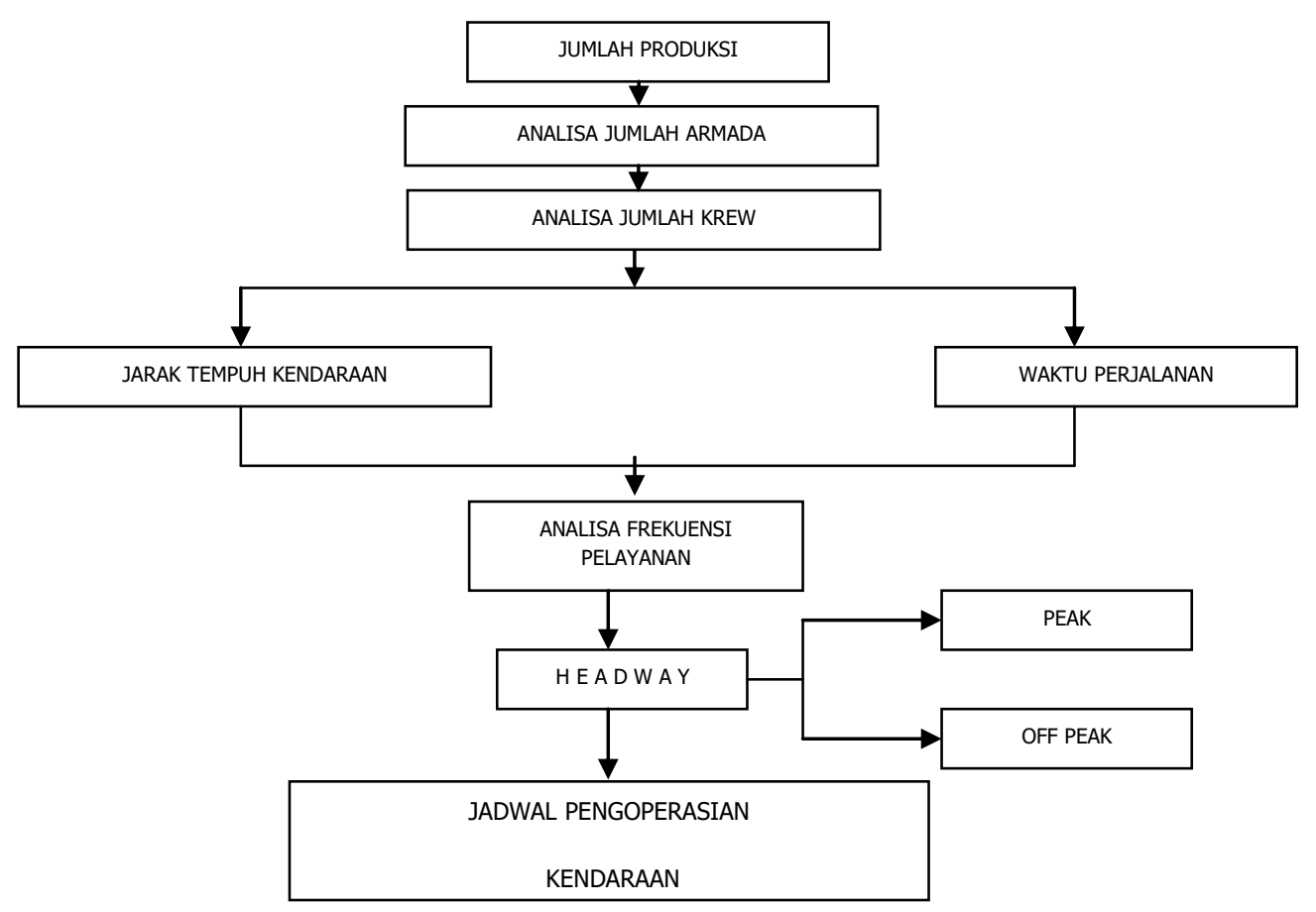

\section{Manajemen Operasional Angkutan Barang}

\section{1) Integrasi Angkutan Barang dengan Dry Port}

Adanya dry port memberikan kemudahan terkait dengan pemindahan barang khususnya menuju ke pelabuhan, dimana dengan penggunaan dry port akan mengurangi pembebanan lalu lintas di sekitar kawasan Jababeka. Terkait denga adanya dry port, maka perlu adanya integrasi antara seluruh kawasan industry Jababeka dengan dry port dimana hal ini terkait dengan pengiriman barang dari masing-masing kawasan menuju/dari dry port yaitu dengan mempertimbangkan tingkat kapasitas dry port dan juga kondisi lalu lintas.

\section{2) Waktu Operasional Pengangkutan}

Waktu operasional angkutan barang hendaknya juga diterapkan seperti pada system waktu operasional pergantian shift karyawan yaitu dengan membagi kedalam kelompokkelompok industry pada jam-jam tertentu, sehingga dalam pembebanan ke dalam jaringan 
jalan tidak secara bersama-sama.Dengan cara seperti ini maka kondisi lalu lintas dapat berjalan lancar.

\section{Manajemen Parkir Angkutan Barang dan Karyawan}

Pengaturan parkir kendaraan angkutan barang, kendaraan antar jemput maupun untuk kendaraan karyawan sangatlah penting, dimana masalah ini terutama untuk parkir kendaraan antar jemput karyawan merupakan salah satu isu permasalahan yang terjadi sekarang.Namun karena tidak adanya data rincian penggunaan kawasan maka belum dapat dilakukan prediksi penggunaan parkir.Oleh karena itu terkait dengan pengaturan parkir dilakukan dalam kajian tersendiri.

\section{KESIMPULAN DAN SARAN}

\section{A. KESIMPULAN}

1. Pada kondisi tanpa pembangunan kawasan industri Jababeka di tahun 2021, total waktu perjalanan sebesar 4019,1 kend-jam dengan kecepatan jaringan sebesar $27,34 \mathrm{~km} / \mathrm{jam}$.

2. Pada saat Kawasan Industri Jababeka dioperasikan secara maksimal tanpa pengaturan pada tahun 2021 kondisi Do-Nothing total waktu perjalanan disekitar lokasi di bangunnya Kawasan Industri Jababeka sebesar 4401,1 kend-jam, dengan kecepatan jaringan sebesar $23,85 \mathrm{~km} / \mathrm{jam}$.

3. Pada kondisi Do- Something pada tahun 2021 total waktu perjalanan 4367,1 kend-jam, dengan kecepatan jaringan naik menjadi $24,8 \mathrm{~km} / \mathrm{jam}$.

4. Permasalahan yang timbul seperti diuraikan diatas disebabkan adanya beberapa faktor yang menyebabkan turunnya kondisi unjuk kerja pada jalan di sekitar Kawasan Industri Jababeka dan penanganannya:

5. Antisipasi dampak perlu dilakukan untuk menjamin keselamatan pada akses keluar-masuk Kawasan Industri Jababeka, kemudahan manuver pada akses keluar-masuk, serta pemisahan sirkulasi pejalan kaki dengan sirkulasi kendaraan.

6. Potensi tarikan perjalanan yang menuju Kawasan Jababeka pada tahun mendatang perlu dilakukan antara lain:

a. Waktu Operasional Karyawan 

b. Penggunaan Bus Angkutan Jemputan Karyawan
c. Penyediaan Mess karyawan/Condominium khusus untuk karyawan Kawasan Jababeka.
d. Penyediaan angkutan internal kawasan Jababeka dan fasilitas pejalan kaki
e. Pengaturan sirkulasi kendaraan internal didalam masing-masing kawasan dan juga antar kawasan Jababeka secara umum.

f. Adanya Manajemen Operasional Pengangkutan Barang

\section{B. SARAN}

Beberapa saran yang diusulkan adalah sebagai berikut :

1. Usulan dengan perubahan desain dan dilakukannya rekasaya pada skenario 1, 2 dan 3 perlu adanya koordinasi dengan instansi terkait dengan upaya menghindari potensi kemacetan di beberapa ruas jalan dan persimpangan kawasan cikarang dry port

2. Diperlukan Koordinasi dengan instansi terkait perihal rencana akses Tol baru Jakarta-Cikampek.

3. Perlunya Koordinasi kepada intansi terkait berkaitan dengan pengoperasian kendaraan angkutan barang tidak mempengaruhi lalu lintas eksternal jaringan jalan sekitar pada Kawasan Industri Jababeka.

4. Perlunya pengawasan dan evaluasi unjuk kerja lalu lintas sekitar setelah Kawasan Industri Jababeka terbangun dan beroperasi. 


\section{DAFTAR PUSTAKA}

Ahmad M, 2006, Manajemen Lalu Lintas Perkotaan, Beta Offset, Yogyakarta

Bustam H.A, 2015, Pengaruh Penggunaan Dry Port Terhadap Biaya Angkut Batubara di Kabupaten Way Kanan, Skripsi Fakultas Teknik Universitas Lampung, Lampung

Herzog B.O, 2013, Angkutan Barang Perkotaan di Kota-Kota Negara Berkembang, Gesellschaft fur Internationale Zusammenarbeit (GIZ), Germany

Khisty C.J and Lall B.K, 2005, Dasar-dasar Rekayasa Transportasi, Erlangga, Jakarta

Morlok E.K, 1984, Pengantar Teknik dan Perencanaan Transportasi, Erlangga, Jakarta

Mahmudah N, Parikesit D dkk, 2011, Pengembangan Metodologi Perencanaan Transportasi Barang Regional, Jurnal Transportasi Vol 11 No. 3 Desember 2011 : 173-182

Miro F, 2012, Pengantar Sistem Transportasi, Erlangga, Jakarta

Tamin O.Z, 2008, Perencanaan, Permodelan, dan Rekayasa Transportasi, ITB, Bandung

Undang-Undang No.22 Tahun 2009 Tentang Lalu Lintas dan Angkutan Jalan

Peraturan Pemerintah Republik Indonesia No.79 Tahun 2013 Tentang Jaringan Lalu Lintas dan Angkutan Jalan

Direktorat Jenderal Bina Marga, 1997, Manual Kapasitas Jalan Indonesia, Kementerian Pekerjaan Umum Direktorat Jenderal Bina Marga, Jakarta 